\title{
Appropriate use criteria for amyloid PET: A report of the Amyloid Imaging Task Force, the Society of Nuclear Medicine and Molecular Imaging, and the Alzheimer's Association
}

\author{
Keith A. Johnson ${ }^{\mathrm{a}}$, Satoshi Minoshima ${ }^{\mathrm{b}}$, Nicolaas I. Bohnen ${ }^{\mathrm{c}}$, Kevin J. Donohoe ${ }^{\mathrm{d}}$, \\ Norman L. Foster ${ }^{\mathrm{e}}$, Peter Herscovitch ${ }^{\mathrm{f}}$, Jason H. Karlawish ${ }^{\mathrm{g}}$, Christopher C. Rowe ${ }^{\mathrm{h}}$, \\ Maria C. Carrillo ${ }^{i}$, , Dean M. Hartley ${ }^{i}$, Saima Hedrick ${ }^{j}$, Virginia Pappas ${ }^{j}$, William H. Thies ${ }^{i}$ \\ ${ }^{a}$ Departments of Radiology and Neurology, Massachusetts General Hospital, Harvard Medical School, Boston, MA, USA \\ ${ }^{b}$ Department of Radiology, University of Washington, Seattle, WA, USA \\ ${ }^{c}$ Departments of Radiology and Neurology, University of Michigan, and VA Ann Arbor Healthcare System, Ann Arbor, MI, USA \\ ${ }^{d}$ Beth Israel Deaconess Medical Center, Boston, MA, USA \\ ${ }^{e}$ Department of Neurology, University of Utah, Salt Lake City, UT, USA \\ ${ }^{f}$ PET Department, NIH Clinical Center, National Institutes of Health, Bethesda, MD, USA \\ ${ }^{g}$ Department of Medicine, University of Pennsylvania, Philadelphia, PA, USA \\ ${ }^{h}$ Department of Nuclear Medicine and Centre for PET, Austin Health, Victoria, Australia \\ ${ }^{i}$ Division of Medical and Scientific Relations, Alzheimer's Association, Chicago, IL, USA \\ ${ }^{j}$ Society of Nuclear Medicine and Molecular Imaging, Reston, VA, USA
}

Abstract

Positron emission tomography (PET) of brain amyloid $\beta$ is a technology that is becoming more available, but its clinical utility in medical practice requires careful definition. To provide guidance to dementia care practitioners, patients, and caregivers, the Alzheimer's Association and the Society of Nuclear Medicine and Molecular Imaging convened the Amyloid Imaging Taskforce (AIT). The AIT considered a broad range of specific clinical scenarios in which amyloid PET could potentially be used appropriately. Peer-reviewed, published literature was searched to ascertain available evidence relevant to these scenarios, and the AIT developed a consensus of expert opinion. Although empirical evidence of impact on clinical outcomes is not yet available, a set of specific appropriate use criteria (AUC) were agreed on that define the types of patients and clinical circumstances in which amyloid PET could be used. Both appropriate and inappropriate uses were considered and formulated, and are reported and discussed here. Because both dementia care and amyloid PET technology are in active development, these AUC will require periodic reassessment. Future research directions are also outlined, including diagnostic utility and patient-centered outcomes.

(C) 2013 The Alzheimer's Association. All rights reserved.

Keywords: $\quad$ Guidelines; AUC; Imaging; Amyloid; MCI; Alzheimer’s; PET; Florbetapir; Biomarker; Beta-amyloid; Dementia; Radiopharmaceutical

\section{Introduction}

Research progress in Alzheimer's disease (AD) and molecular imaging during the past decade has made it possible

(C) 2013 by the Alzheimer's Association, and the Society for Nuclear Medicine and Molecular Imaging.

This article is being published jointly in Alzheimer's \& Dementia, and The Journal of Nuclear Medicine.

*Corresponding author. Tel.: +312 335 5722; Fax: +866 7413716 .

E-mail address: maria.carrillo@alz.org to detect human brain amyloid $\beta$ (A $\beta)$ deposition during life using positron emission tomography (PET). Parallel progress has improved our understanding of $A \beta$ as an important and therapeutically targetable component of AD pathology. Although $A \beta$ plaques are one of the defining pathological features of $\mathrm{AD}$, many otherwise normal elderly people have elevated levels of $A \beta$, as do patients with clinical syndromes other than AD dementia. The potential clinical utility of $\mathrm{A} \beta$ PET therefore requires careful consideration so that its role may be identified and placed in the proper 
clinical context. The Society of Nuclear Medicine and Molecular Imaging (SNMMI) and the Alzheimer's Association (AA) have jointly developed this article to assist in the appropriate use of this class of PET radiopharmaceuticals. The primary goal of this article is to provide health care practitioners with the information necessary to provide their patients with optimal care while also considering the costeffective use of limited health care resources.

\section{Background}

With the advent of carbon-11 (C-11)-labeled Pittsburgh compound $\mathrm{B}(\mathrm{PiB}), \mathrm{A} \beta$ - or amyloid PET-emerged as a major element in a transformation of $\mathrm{AD}$ research that emphasized the development of biomarkers that could potentially facilitate drug development [1]. Intense efforts were directed at assessing the amyloid status of individuals with $\mathrm{AD}$ dementia as well as those with prodromal and preclinical stages of disease, and the technology was adopted rapidly worldwide, albeit largely in specialized research centers. More recently, amyloid PET has been used increasingly in clinical trials for AD therapeutics. Because the short 20minute half-life of $\mathrm{C}-11$ limits routine clinical use of $\mathrm{PiB}$ as a result of the need for an onsite cyclotron, amyloidbinding radiopharmaceuticals labeled with longer lived fluorine-18, with a 110-minute half-life, were developed and commercialized for wide availability. One such compound, [F-18]florbetapir, achieved approval by the U.S. Food and Drug Administration in April 2012. The European Medicines Agency's Committee for Medicinal Products for Human Use recommended marketing authorization for [F-18]florbetapir in October 2012.

To develop this article, the Amyloid Imaging Taskforce (AIT), consisting of experts in the fields of imaging, neurology, and dementing diseases was assembled by the AA and SNMMI to review the available literature and develop consensus recommendations for the clinical use of these promising new radiopharmaceuticals. At the time of this review, experience with clinical amyloid PET imaging is limited. Most published studies to date have been designed to validate this technology and understand disease mechanisms rather than to evaluate applications in clinical practice. As a result, published data are available primarily from highly selected populations with prototypical findings rather than from patients with comorbidities, complex histories, and atypical features often seen in clinical practice. Despite these limited clinical use data, the members of the task force concluded that the proven sensitivity and specificity of the new radiopharmaceuticals for brain amyloid, and the known association between brain $A \beta$ deposition and $A D$ suggest these new radiopharmaceuticals could potentially be helpful in the workup and diagnosis of patients with cognitive impairment.

Translation of research findings to clinical populations poses substantial challenges. Unlike research subjects, clinical patients can exhibit a wide range of medical and psychiatric problems. Indeed, the prevalence of mixed-cause dementia increases with advancing age and is frequently seen in clinical practice [2]. As the population ages, individuals are increasingly likely to inquire about the usefulness of amyloid PET imaging in a variety of circumstances that are unlikely to be addressed in the scientific literature. In addition, as amyloid imaging agents become more well-known and longitudinal data accumulate, patients and referring physicians may request amyloid PET imaging for individuals who are asymptomatic. Colleagues may also ask for advice about using amyloid PET imaging for purposes such as screening someone with a family history of AD dementia, or for use in patients already carrying a diagnosis of a non-AD dementia.

When the peer-reviewed literature is incomplete, as is often the case, expert opinion can be valuable, particularly when considering numerous practical clinical issues and ethical concerns that largely remain overlooked in the design and discussion of published clinical trials. There is often diagnostic uncertainty resulting from the complexities of patient history as well as the inconsistencies in examination results. Incorporating amyloid imaging into clinical decision making may help to narrow a differential diagnosis and simplify some of the complexities inherent in evaluating patients with mild cognitive impairment (MCI) and dementia.

Although identifying potential benefits, the AIT concluded that an amyloid PET report will not constitute and is not equivalent to a clinical diagnosis of AD dementia. Imaging is only one tool among many that clinicians should use judiciously to manage patients. Amyloid PET imaging does not substitute for a careful history and examination. Indeed, the history and examination are required to understand the clinical context necessary to incorporate imaging results into clinical decision making. The diagnosis of dementing diseases has implications that resonate beyond the patient to include family members, particularly those who are genetically related. We hope that these recommendations will be relevant to many patients, even when published evidence may be lacking.

As with most guidelines, the health care provider has to make the ultimate judgment regarding the care of each individual patient. The AIT sought to assist this process and identified the following general sequence of events with which amyloid PET could be used according to the appropriate use criteria (AUC) set forth here: $(i)$ evaluation by a dementia expert to assess the need for diagnostic testing, possibly to include amyloid PET, if the AUC are met; (ii) referral to a qualified provider of amyloid PET services; (iii) performance, interpretation, and reporting of the amyloid PET result according to established standards; (iv) incorporation of the PET result into the clinical assessment process by the dementia expert; and ( $v)$ disclosure of the PET result by the dementia expert to the patient and caregivers, along with discussion of the result and its management consequences. The health care provider must bear in mind that amyloid imaging does not make a diagnosis of $\mathrm{AD}$, and by itself does not determine that a patient's cognitive impairment is a result of AD pathology. 


\section{Methods}

The AIT formulated AUC for amyloid PET imaging using procedures similar to those used by groups such as the American College of Cardiology Foundation [3]. The process used (i) identification of potential indications/nonindications, (ii) evidence assessment and rating, (iii) group rating of potential indications/nonindications, (iv) discussion and revoting, and $(v)$ writing. Three AIT subcommittees were established: the Indication Subcommittee, the Literature Subcommittee, and the Evidence Review Subcommittee (see Appendix A).

\subsection{Possible indications and nonindications of clinical scenarios}

The Indication Subcommittee, consisting of practicing dementia specialists and imaging experts, discussed 115 potential indications and nonindications based on multiple clinical and nonclinical scenarios with variables including symptoms, clinical setting, clinical context, evidence of cognitive deficit, family history, knowledge of AD genetic risk, and age. This process is described in Appendix B. Based on the consensus discussion, the Indication Subcommittee consolidated potential indications and nonindications into 14 scenarios that were subsequently incorporated in a data extraction form used for the evidence assessment (described later).

\subsection{Evidence review and analytical framework}

The Literature Subcommittee used a search strategy as established by the American Academy of Neurology and the Institute of Medicine of the National Academy of Sciences to identify relevant literature. The process is described in Appendix C. The AIT deliberated on the choice of literature screening criteria, and a decision was made on the basis of the types of evidence ultimately needed to establish clinical utility of amyloid PET. The ultimate goal was to determine whether there is evidence that using amyloid PET leads to clinically meaningful improvement in outcomes or is useful in medical or personal decision making. Because direct evidence linking amyloid PET to health outcomes is currently lacking, the AIT evaluated existing literature according to a possible chain of evidence consisting of three key questions, adapted from the scheme of Fryback and Thornbury [4]:

The first question deals with technical efficacy (analytical validity or technical test performance). This class of evidence reflects the stability, adequacy, and reproducibility of the test itself, and includes both the image data and the qualitative image interpretation. Proof of technical efficacy includes reproducibility of specific amyloid PET acquisition procedures and protocols under standardized conditions, which must be established separately for each amyloid tracer and must be applicable to the range of PET instrumentation in common use. In addition, the implementation of amyloid PET requires a qualitative read of images, so that evidence of standardized interpretation protocols that lead to acceptable levels of interrater agreement must be considered. These standards and procedures are ultimately the province of the professional certifying organizations, such as the American Board of Nuclear Medicine, but reports have already appeared from the Alzheimer Disease Neuroimaging Initiative [5] and phase 2 industry-sponsored trials [6] that describe standardized acquisition protocols for F-18-labeled PET ligands as well as interpretation standards. Such standards and procedures have been implemented by the commercial developers of the F-18 amyloid PET ligands, and evidence of validation is required by the U.S. Food and Drug Administration before approval for clinical use is granted. Additional analytical validity data should be acquired relating to test-retest and longitudinal stability and change. Web-based instruction programs for readers of F-18 amyloid PET have been developed and validated, and should be completed successfully by all imaging specialists prior to reading of clinical amyloid PET (see Image Quality and Reporting).

The second question deals with diagnostic accuracy (clinical validity) based on an autopsy truth standard. Considerable progress has been achieved to establish clinical validity using histopathology-to-image comparisons. As with other elements of validation, each tracer and its associated interpretation protocol must be assessed separately. The AIT elected to include longitudinal clinical studies as ancillary evidence of clinical or diagnostic validity when the design included a baseline amyloid PET followed by clinical evaluation and assessment of longitudinal decline or conversion in clinical status, according to accepted clinical diagnostic criteria $[7,8]$.

The third question deals with clinical utility based on a change in management (including change in diagnostic evaluation) and associated improved clinical outcomes. This is the most challenging component of the analytical framework, and the evidence for a change in clinical management based on amyloid PET is not yet available. With only medications to treat symptoms currently available and no disease-modifying treatment yet proved, the clinical utility of a diagnostic test to alter patient management and result in a quantifiable benefit is very difficult to establish. However, an accurate diagnosis of the cause of cognitive impairment is often critically important for a practitioner to select appropriate treatments and avoid inappropriate interventions. Furthermore, different dementing diseases have distinctive courses, complications, and comorbidities that alter nonpharmacological management and treatment recommendations. Although psychological, social, economic, and family outcome variables, including value of knowing, can be identified as potentially altering management, the data supporting specific outcomes for amyloid PET are not yet available. 
Multiple searches were performed using the National Institutes of Health's PubMed. The Literature Subcommittee reviewed the list for inclusion and identified a subset of documents by abstract analysis. Documents not relevant to the clinical use of amyloid PET were eliminated based on the primary focus of the reported study and data presented in the document. In addition, to ensure appropriate documents were captured during the initial search and review, the AIT performed a backward review to crosscheck the literature included in seminal amyloid imaging reviews with those included in the AIT's initial assessment. For the backward review, the AIT used the bibliographies of Klunk [9], Villemagne and colleagues [10], and Laforce and Rabinovici [11].

The Literature Subcommittee developed a data extraction form for evidence assessment. The Evidence Review Subcommittee conducted evidence assessment in two steps. During the phase I review, valid documents identified during the initial review process were assigned to a pair of reviewers (a dementia specialist and an imaging specialist). Each reviewer scored the documents using the data extraction form. Other documents that met the preliminary inclusion criteria, as indicated by both reviewers, but that received low scores by both reviewers, or mixed scores, or strong reviewer comments for further assessment were also identified as documents to be discussed. During the phase II review, additional documents were identified through the backward review and an updated search, as well as new papers in press. A second round of reviews was conducted identical to phase I. The final inclusion criteria were that the document must contain data of one of two types-either PET-histopathology correlation or PET correlation with longitudinal clinical follow-up. After the review, co-chairs of the AIT reviewed the findings of both phase I and phase II and presented a final list of 23 documents that satisfied the final inclusion criteria and these were presented to the full AIT [5,12-33]. These documents were used as the literature-based evidence for rating the AUC outlined by the Indication Subcommittee.

\subsection{Rating of the AUC}

The group rating of potential indications/nonindications was conducted using a rating sheet by individual voting AIT members without knowledge of other members' rating results. Fourteen scenarios proposed by the Indication Subcommittee were consolidated to 10 possible indications/nonindications by defining a preamble that applies to all indications/nonindications. The rating sheet included $(i)$ the final 10 possible indications/nonindications, (ii) the amount of qualified evidence determined by the evidence assessment, and (iii) individual documents that relate to each indication/nonindication. Based on the presented evidence and individual AIT members' opinions, the AIT members were asked to rate each indication/nonindication with Appropriate, Uncertain, or Inappropriate. A nonvoting AIT member summarized the rating results.

\section{Definitions}

The following terms are used in the AUC:

Dementia expert a physician experienced in the assessment and diagnosis of dementia. The AUC depend heavily on the training, experience, and clinical judgment of the dementia experts ordering the test and their application of the published, standardized clinical criteria for $\mathrm{MCI}$ and $\mathrm{AD}$ (as defined in this list). Expertise in applying these criteria is typically acquired through formal training and clinical experience in neurology, psychiatry, and geriatric medicine; however, not all physicians in these disciplines are dementia experts.

Alzheimer's disease (AD) the pathological process reflected in specific postmortem histopathological criteria [34], which is frequently but not necessarily associated with a characteristic dementia syndrome $[7,8]$. The AD pathological process differs conceptually and is uncoupled from the dementia syndrome with which it is associated, as evidenced by the very long preclinical or asymptomatic period preceding the dementia syndrome. The AUC specifically refer to clinical criteria for $\mathrm{AD}$ dementia that have recently emerged from the National Institute on Aging-Alzheimer's Association work group [7] and the international work group [8]. Core clinical criteria for $\mathrm{AD}$ dementia identify the specific conditions and circumstances under which a dementia expert may determine whether amyloid PET can be used appropriately. Although the two international work groups used different terms-probable $\mathrm{AD}$ and typical $\mathrm{AD}$ - the underlying principles are quite similar, and either nomenclature may be applied to support the conclusion that amyloid PET would or would not be appropriate (criterion 4).

Probable AD dementia a clinical syndrome meeting the core clinical criteria specified in the National Institute on Aging-Alzheimer's Association work group report [9] (also see [35])

Possible AD dementia a clinical syndrome meeting the core clinical criteria for $A D$ dementia in terms of the nature of the cognitive deficits for $A D$ dementia, but either (i) has a sudden onset of impairment or demonstrates insufficient historical detail or objective documentation of progression, or (ii) has an etiologically mixed presentation because of evidence of vascular or Lewy pathology [7]

Mild cognitive impairment (MCI) a clinical syndrome meeting the published core clinical criteria for MCI [3638] (also see [8,35,39]). Although considerable debate and evolution of the criteria for MCI continue, general agreement exists about the core features. Briefly, these include (i) concern about a change in cognition, (ii) impairment in one or more cognitive domains, (iii) preservation of independence in functional activities, but (iv) not demented [38]. The application of these criteria and their use in determining whether amyloid PET would be appropriate is in the hands of the dementia expert. 
Table 1

F-18 beta-amyloid PET radiopharmaceuticals compared to C-11 PiB

\begin{tabular}{|c|c|c|c|}
\hline $\begin{array}{l}\text { Ligand compared } \\
\text { with } \mathrm{C}-11 \mathrm{PiB}\end{array}$ & Subjects & $\begin{array}{l}\text { Correlation of binding between } \\
\text { ligands }\end{array}$ & Diagnostic performance \\
\hline Florbetapir [55] & $\begin{array}{l}12 \text { AD patients, } 14 \text { cognitively normal } \\
\text { control subjects }\end{array}$ & $\begin{array}{l}\text { Composite cortical binding correlation } \\
\quad r=0.78, P<.001\end{array}$ & $\begin{array}{l}\text { Group discrimination florbetapir area under } \\
\text { the curve }=0.90 \mathrm{vs} \mathrm{PiB}=1.0 \text {. }\end{array}$ \\
\hline Florbetapir [56] & $\begin{array}{l}24 \text { MCI subjects, } 8 \text { healthy control } \\
\text { subjects }\end{array}$ & $\begin{array}{l}\text { Composite cortical binding correlation } \\
\rho=0.95, P<.001, \text { slope }=0.60\end{array}$ & $\begin{array}{l}97 \% \text { classification agreement using derived } \\
\text { cut points }\end{array}$ \\
\hline Flutemetamol [48] & $20 \mathrm{AD}$ patients, $20 \mathrm{MCI}$ subjects & $\begin{array}{l}\text { Composite cortical binding correlation } \\
r=0.905, \text { slope }=0.99\end{array}$ & $\begin{array}{l}100 \% \text { concordance of individual subject } \\
\text { visual scan categorization between ligands }\end{array}$ \\
\hline NAV4694 [53] & $\begin{array}{l}7 \text { AD patients, } 3 \text { patients with } \\
\text { frontotemporal dementia, } 10 \mathrm{MCI} \\
\text { subjects, } 25 \text { healthy control subjects }\end{array}$ & $\begin{array}{c}\text { Composite cortical binding correlation } \\
r=0.99, P<.0001, \text { slope }=0.95\end{array}$ & $\begin{array}{l}100 \% \text { concordance of individual subject } \\
\text { visual scan categorization between ligands }\end{array}$ \\
\hline
\end{tabular}

Abbreviations: PiB, Pittsburgh compound B; AD, Alzheimer's disease; MCI, mild cognitive impairment.

Amyloid positivity/negativity the determination by an imaging expert that the amyloid PET scan indicates the presence or absence of $A \beta$ plaque. The imaging expert is a nuclear medicine specialist or radiologist with specific training in the interpretation of amyloid PET. The amyloid PET data must be technically adequate and must be acquired at a fully qualified and certified facility (see Image Quality and Reporting). The protocol for the qualitative read that determines positivity or negativity must be standardized (e.g., [5]) and must conform to a specific guideline provided by the manufacturer if it is available.

\section{PET A $\beta$ radiopharmaceuticals}

Although a number of $\mathrm{A} \beta$ PET radiopharmaceuticals have been reported with human data [40-43], currently there are five that are in use at multiple sites to image Alzheimer pathology in vivo. Among these, [C-11]-(2-[4methyl-amino phenyl]-1,3-benzothiazol-6-ol), or PiB, was the first to be described and is the most extensively studied [1]. PiB, a neutral analog of the histological dye thioflavin $\mathrm{T}$, has been evaluated with respect to clinical syndromic and postmortem histopathological correlation over approximately 10 years in several clinical populations and in healthy control subjects. Histopathological correlation data demonstrate the association between PiB PET and postmortem assessment of A $\beta$ pathology [1214,23,30,44-47].

The short 20-minute half-life of $\mathrm{C}-11$ limits routine clinical use because of the need for an onsite cyclotron, whereas the 110-minute half-life of F-18-labeled PET ligands allows incorporation of PET into routine clinical practice, as has occurred with [F-18]fluorodeoxyglucose (FDG) in clinical oncology. Several F-18-labeled A $\beta$ PET radiopharmaceuticals have been developed, including [F-18]3'-F-PiB (flutemetamol) [25], [F-18]AV-45 (florbetapir) [15], [F-18]-AV-1 or [F-18]-BAY94-9172 (florbetaben) $[49,50]$, and [F-18]-AZD4694 or NAV4694 [5153]. Postmortem histopathology-to-PET correlations have been published for florbetapir [15], and biopsy
histopathology-to-PET correlations have been published for flutemetamol [54].

F-18 ligand PET data have been compared quantitatively with $\mathrm{C}-11 \mathrm{PiB}$ data acquired in the same subjects with respect to cortical binding, linear regression slope, and diagnostic classification performance (Table 1). Wolk and colleagues [55] performed PiB and florbetapir PET imaging in 14 cognitively normal adults and $12 \mathrm{AD}$ patients and showed that both ligands displayed highly significant group discrimination and correlation of regional uptake. Landau and associates [56] compared $\mathrm{PiB}$ with florbetapir and found the data were correlated at $r=0.95$ and a slope of 0.60 , and that resulting cut points yielded classification agreement in $97 \%$ of cases evaluated. A correlation with PiB of $r=0.905$ and a slope of 0.99 was reported for flutemetamol in $20 \mathrm{AD}$ patients and $20 \mathrm{MCI}$ patients, in which the concordance of visual reads between ligands was $100 \%$ [48]. Villemagne and coworkers [57] compared PiB with florbetaben in 10 healthy control subjects and 10 patients with $\mathrm{AD}$ and reported the correlation to be $r=$ 0.97 , the slope to be 0.71 , and the concordance between ligands to be $100 \%$. Rowe and colleagues [53] compared NAV4694 with PiB in seven patients with AD, three patients with frontotemporal dementia (FTD), 10 patients with MCI, and 25 healthy control subjects and found the correlation to be $r=0.99$, the slope to be 0.95 , and classification concordance to be $100 \%$. These findings are consistent with a high correlation of these [F-18]-labeled ligands with $\mathrm{PiB}$ and they support the translation of PiB PET findings into the domain of these [F-18]-labeled radiopharmaceuticals. Comparison studies of one F-18 agent with another have not yet been reported.

\section{Results of ratings}

Ratings for each indication/nonindication were obtained from independent voting by eight AIT voting members, and the results were summarized by a nonvoting member. At the time of voting, each member was able to access qualified peer-reviewed documents that potentially concern each 
possible indication, and ratings by AIT members of the quality of the evidence, based on the results of the literature review as described previously. For each indication, the number of supporting publications and the average quality of evidence were indicated on the voting sheet.

During the initial voting, four possible indications and seven possible nonindications were submitted for voting. Substantial disparities in voting results $(30 \%-50 \%)$ were found for four potential indications. Each potential indication/nonindication was reviewed in subsequent AIT discussions, and uncertain language in the proposed AUC were clarified for revoting. During this process, two possible indications were combined into one indication, resulting in total three possible indications and seven possible nonindications.

In the revoting results, the ratings of Appropriate or Inappropriate were unanimous for possible indications 1 and 2, and possible nonindications 4 to 10 . For indication 3, two voting members voted Uncertain whereas the other six voting members voted Appropriate.

\subsection{Appropriate use criteria}

Amyloid imaging is appropriate in the situations listed here for individuals with all of the following characteristics:

Preamble: $(i)$ a cognitive complaint with objectively confirmed impairment; (ii) AD as a possible diagnosis, but when the diagnosis is uncertain after a comprehensive evaluation by a dementia expert; and (iii) when knowledge of the presence or absence of $A \beta$ pathology is expected to increase diagnostic certainty and alter management.

1. Patients with persistent or progressive unexplained MCI

2. Patients satisfying core clinical criteria for possible $\mathrm{AD}$ because of unclear clinical presentation, either an atypical clinical course or an etiologically mixed presentation

3. Patients with progressive dementia and atypically early age of onset (usually defined as 65 years or less in age) tions:

Amyloid imaging is inappropriate in the following situa-

4. Patients with core clinical criteria for probable $A D$ with typical age of onset

5. To determine dementia severity

6. Based solely on a positive family history of dementia or presence of apolipoprotein E (APOE) $\varepsilon 4$

7. Patients with a cognitive complaint that is unconfirmed on clinical examination

8. In lieu of genotyping for suspected autosomal mutation carriers

9. In asymptomatic individuals

10. Nonmedical use (e.g., legal, insurance coverage, or employment screening)

\section{Discussion of individual indications}

\subsection{Preamble}

The AIT considered whether to specify the patient characteristics for each indication separately, but recognized that there were several elements common to all appropriate indications and set these elements apart in a separate preamble. The preamble was intended to characterize all patients for whom the appropriate indications 1 to 3 apply.

The preamble restricts substantially the set of patients for whom amyloid imaging would be appropriate in several ways. First, the dementia expert, as defined earlier (Definitions), must evaluate the patient and determine that there is objective evidence of impairment. The objective evidence may be acquired and interpreted directly by the dementia expert in a detailed mental status examination or obtained from a separate neuropsychological assessment. Second, the expert should evaluate all available clinical evidence, including the history, physical and neurological examinations, and all available laboratory and neuroimaging data to consider the possible causes of the illness as well as potentially confounding circumstances such as depression, medication effects, and cerebrovascular, endocrine, or other medical disorders. This is because the presence of amyloid pathology in the brain, when considered in isolation, is insufficient to determine the cause of the impairment; rather, the presence of amyloid pathology is one factor among many that must be considered. The dementia expert must conclude on the basis of all available evidence that (i) the cause of the impairment is uncertain and (ii) that it could be explained on the basis of $\mathrm{A} \beta$ pathology (i.e., AD dementia or its prodromal stage must be in the differential diagnosis).

Last, the expert must conclude that a determination of either amyloid positivity or amyloid negativity would both increase the level of diagnostic certainty and alter the plan for patient management. Empirical evidence for the value of added certainty resulting from amyloid PET has not yet been reported; however, several patient-centered outcome studies are underway, and the following should serve to guide efforts of this type further. The AIT considered several situations in which the added certainty of amyloid PET could be useful to patients and caregivers, and could result in altered management. First, many patients with uncertain diagnoses undergo extensive and repeated testing that would be reduced if the diagnostic certainty were increased by amyloid PET. For others, however, it is also likely that amyloid negativity would require additional diagnostic testing as the dementia expert seeks to identify the underlying A $\beta$-negative cause of impairment. The relative utility of diagnostic tests should be evaluated further. Second, increased certainty of the diagnosis could provide a basis for earlier and more consistent drug treatment, avoidance of treatments unlikely to afford benefit, and improved monitoring for likely complications and adverse drug effects that are relevant to specific dementing diseases. In addition, improved diagnostic 
certainty could provide more powerful motivation to make required lifestyle changes and difficult living transitions for which they are otherwise reluctant. Third, a more certain diagnosis can have profound social benefits to patients and families, who may need to identify the required resources and plan for future management. Minimizing diagnostic uncertainty can assist in bringing family members to a uniform understanding of the patient's condition and needs, facilitating the development of a unified plan of progressive support that best manages financial resources and maximizes quality of life.

Although learning the cause of dementia and the limited efficacy of available treatments may cause stress and anxiety for some, we believe that the value of knowing outweighs the disadvantages. Electing to manage dementing diseases without investigating the cause or with high levels of diagnostic uncertainty often contributes to inconsistent and poor quality of care. In any circumstance, patients and their families decide — on their own — whether to seek answers by electing or failing to seek care.

\subsection{Indication 1 (appropriate): Patients with persistent or progressive unexplained $M C I$}

This indication refers to a patient who satisfies all the criteria set forth in the preamble and is being evaluated for persistent or progressive cognitive impairment that is still mild (e.g., a patient with MCI as defined earlier). This means, in practice, that although impaired according to objective measures, the patient does not have "significant interference in the ability to function at work or in usual daily activities" (pg 265) [7] (also see [8]). In this circumstance, an amyloid PET finding of positivity would, on the basis of its known correspondence to brain $A \beta$, raise the level of certainty that the patient's mild impairment is on the basis of $\mathrm{AD}$ pathology and represents early AD dementia (see Definitions). However, it is important to emphasize again that not all patients with MCI would be appropriate for amyloid PET. Rather, amyloid PET would be appropriate only in those individuals who the dementia expert has concluded would benefit from greater certainty of the underlying pathology and whose clinical management would change as a result of this greater certainty.

The dementia expert should recognize that asymptomatic amyloid deposition is common in older (e.g., $>75$ years) individuals and may not be related to a patient's presenting symptoms. Furthermore, the dementia expert will need to consider in older individuals the possibility that amyloid positivity could be present but not the sole factor in causing the impairment and that comorbid conditions or pathologies such as vasculopathy could be present and could account for or significantly contribute to the observed impairment.

The prognostic value of amyloid PET for predicting future outcomes in MCI patients is under active investigation, and preliminary studies are suggestive but not complete. Initial reports suggest that the majority of patients with amnes- tic MCI, variously defined by neuropsychological evaluation, and a positive amyloid PET will progress to $\mathrm{AD}$ dementia, whereas the risk of progression to AD dementia is significantly lower in those who are amyloid negative. The available evidence to date has not definitively linked amyloid positivity in individual patients with a future time point when cognitive or functional deterioration can be predicted. Therefore, currently the use of amyloid PET to predict the trajectory of a patient's cognitive decline or the time to any specific outcome is not appropriate because published evidence is limited (see Further Research Questions).

A related, alternative scenario for this indication is a patient, also satisfying all the criteria set forth in the preamble, who is amyloid negative and therefore much less likely to be impaired on the basis of $\mathrm{AD}$. The amyloid-negative scenario may, in practice, be the most frequently useful scenario in MCI, given the potential confound of age-associated $A \beta$, discussed earlier, among amyloid-positive individuals. Thus, in patients with MCI whose clinical picture may be complicated with potential vascular, traumatic, or medical causes of cognitive impairment, amyloid PET may find utility and could be used appropriately to exclude AD pathology effectively as a basis for the clinical syndrome.

\subsection{Indication 2 (appropriate): Patients satisfying core clinical criteria for possible $A D$ (i.e., atypical clinical course or etiologically mixed presentation)}

This indication refers to a patient with an established dementia syndrome who is not typical with regard to presentation and clinical course, or to a patient who is considered to have a mixture of causal pathological processes. It is intended to explicitly exclude from the category of appropriate use the patient about whom there is little doubt of the underlying pathology because the onset, course, and examination findings are typical of AD dementia. It is, however, intended to include those patients for whom substantial uncertainty exists and for whom greater confidence would result from determining whether $\mathrm{A} \beta$ pathology is present or not present, as described next.

The AIT chose, here, to rely on the established concept of possible AD, specifically as it has been recently revised [7], and again to focus on the dementia specialist as the physician who would apply the criteria based on this diagnostic category. The restriction in this indication to patients with possible AD dementia is based on the well-established existence of patients about whom there is substantial doubt of whether the dementia is based on AD pathology. The sources of doubt are (i) the presence of an unusual course (e.g., sudden onset or episodic) or because the course cannot be established from the history or from retrospective cognitive test data, or (ii) the presence of a comorbid condition that confounds the interpretation of the clinical data, such as cerebrovascular disease, other neurological disease, other medical condition, or medication use that is affecting cognition and function. Amyloid PET is not useful in identifying the 
possible confound of coexisting Lewy pathology (discussed later).

\subsection{Indication 3 (appropriate): Patients with atypically young-onset dementia}

Amyloid PET is appropriate in the scenario in which a relatively young patient (e.g., 50-65 years old, but possibly even younger) presents with a progressive impairment that has features of $\mathrm{AD}$ dementia as well as of a non-AD dementia. In the scenario covered by this indication, the dementia specialist is often called on to identify the cause of a devastating illness in such a patient, and to manage a complex and comprehensive evaluation. The purpose of the evaluation is to manage the symptomatic treatment rationally; make appropriate employment, driving, and lifestyle decisions; possibly refer the patient to clinical trials of candidate disease-modifying therapies; and to provide a basis for prognosis and planning for care. The presence or absence of AD pathology in this circumstance is frequently a critical component of the initial differential diagnosis, and it is well known from postmortem studies that clinical diagnosis based on history and examination is often wrong with regard to the presence of $\mathrm{AD}$ pathology [58].

\subsection{Indication 4 (not appropriate): Patients with core clinical criteria for probable $A D$ with typical age of onset}

As mentioned earlier, the AIT identified seven circumstances or scenarios in which amyloid imaging would be inappropriate. The first is indication 4. The AIT recommended against the use of amyloid PET in cases in which core clinical criteria for probable AD dementia were satisfied [7], and there were typical history and examination findings, because the level of uncertainty would be low and the potential benefit from added information and the potential for altered management would be correspondingly low.

\subsection{Indication 5 (not appropriate): To determine dementia severity}

Data are lacking to support the use of amyloid imaging to determine the severity of any cognitive disorder. Thus far, the predominance of the evidence is that the level of $A \beta$ burden measured with amyloid PET does not correlate well with severity of deficits in patients with dementia [10].

\subsection{Indication 6 (not appropriate): Based solely on a positive family history of dementia or presence of $\mathrm{APOE}$ $\varepsilon 4$}

There are no data currently available that indicate thatbased solely on family history or APOE genotype-that prognosis, course, or greater certainty in the cause of cognitive deficits is aided with amyloid PET imaging.

\subsection{Indication 7 (not appropriate): Patients with a cognitive complaint that is unconfirmed on clinical examination}

The significance of a cognitive complaint in an elderly person without deficits on examination is currently a topic of active investigation; however, there is insufficient evidence to suggest amyloid PET can aid prognostic judgments or relieve the concerns of such individuals. A negative amyloid PET scan today cannot exclude the possibility of AD dementia in the future.

\subsection{Indication 8 (not appropriate): In lieu of genotyping for suspected autosomal mutation carriers}

The use of amyloid PET in lieu of genotyping for suspected autosomal dominant mutation carriers is considered inappropriate. The optimal clinical evaluation in these cases is careful collection of a family history, followed (if appropriate) by genetic counseling prior to and after genetic testing for known mutations. Future use of amyloid PET in autosomal dominant mutation carriers could include determination of whether the amyloid deposition phase of their illness has begun. In the setting of a complete clinical evaluation, including serial neuropsychological testing, this information may be useful in identifying one disease-related milestone that, along with the genetic information, aids decision making.

\subsection{Indication 9 (not appropriate): The clinical use of amyloid PET in asymptomatic individuals}

The prognostic value of amyloid positivity in normal elderly individuals remains investigational (see Further Research Questions). There is a significant potential for patients and families to make inaccurate assumptions about risk and future outcomes on the basis of amyloid PET results. Currently, the potential harms outweigh the minimal benefits. The availability of proven preventative therapies would undoubtedly alter this judgment.

\subsection{Indication 10 (not appropriate): Nonmedical usage}

The AIT did not find any evidence to support the utility of amyloid PET in a context outside of a diagnostic evaluation to determine the cause of cognitive impairment. In particular, no evidence supported a role for amyloid imaging to inform physicians when they are consulted on legal-, disability-, and employmentrelated matters. These include assessing competency, screening for insurability, or assessing employability or the ability to perform activities of daily living such as driving, piloting an aircraft, or making financial decisions. 


\section{Limitations of amyloid PET in clinical evaluation}

A major limitation of amyloid PET to support a diagnosis of $\mathrm{AD}$ dementia is the high prevalence of amyloid positivity in normal older individuals. Population-based studies are only beginning to be reported, but estimates of agespecific positivity rates for amyloid PET are less than 5\% in those 50 to 60 years old, $10 \%$ in those 60 to 70 years old, $25 \%$ in those 70 to 80 years old, and more than $50 \%$ in persons aged 80 to 90 years $[59,60]$. This high ageassociated prevalence means that the causality of $A \beta$ for a patient's clinical syndrome cannot be established with amyloid PET by itself without considering the prior probability of positivity based solely on age. The dementia expert should consider the possibility, prior to ordering amyloid PET, that incidental, age-related amyloid detection may not be related to or relevant to the presenting symptoms of a patient.

Another major caveat is that a positive amyloid scan can also be seen in not only AD, but also in other medical conditions. For example, amyloid PET is frequently positive in dementia with Lewy bodies [61,62]. Amyloid imaging detects both fibrillar amyloid found in blood vessels (cerebral amyloid angiopathy) and interstitial fibrillar amyloid in plaques. Imaging cannot distinguish between amyloid angiopathy and parenchymal fibrillar plaques [32], and both are highly prevalent in the elderly, with or without dementia. Although usually associated with interstitial amyloid plaques, in rare cases amyloid angiopathy can occur alone [63]. Occasionally, amyloid angiopathy unaccompanied by typical pathological features of AD can cause progressive dementia [64,65]. More commonly, amyloid angiopathy can become clinically manifest as a cause of cerebral hemorrhage, and in such cases carries a high risk of recurrence [66,67]. It is important to emphasize that amyloid positivity does not establish the diagnosis of $\mathrm{AD}$ or differentiate it from $A \beta$ disorders such as dementia with Lewy bodies and cerebral amyloid angiopathy.

It is important to note several clinical circumstances in which amyloid PET would not be expected to be useful. First, it would not add any useful information in differentiating disorders that are not associated with $\mathrm{A} \beta$, such as the various FTD syndromes. Second, amyloid PET would not be expected to detect the rare forms of $\mathrm{AD}$ in which ligand binding is greatly reduced as a result of unusual forms of $A \beta[14,68]$. The appropriate use of amyloid PET requires knowledge of all relevant findings of clinical evaluations, laboratory tests, and imaging, relating how each component of the accumulated evidence should be weighed. Thus, clinical amyloid PET should be performed in the context of a comprehensive evaluation undertaken by a clinician with expertise in evaluating cognitive neurodegenerative disorders.

The AIT did not consider other proposed diagnostic biomarkers for $\mathrm{AD}$ and therefore did not draw any conclusions with regard to the relative value of amyloid PET compared with cerebrospinal fluid, magnetic resonance imaging, and FDG-PET (see Further Research Questions).
The AIT considered broader social and psychological implications of amyloid status determination. Although empirical data have not yet been evaluated, the AIT concluded that certain steps should probably be taken by the dementia expert to avoid psychological harm to patients and families that could follow after the initial disclosure of amyloid status. These steps include pretest counseling about the emotional and social implications of both a positive and a negative amyloid PET. Implications in the realms of legal and insurance status, including health, life, and long-term care, and employment ramifications are even less well understood at this time, and policymakers should consider whether existing laws such as the Americans With Disabilities Act provide adequate protection for these patients. Notably, the U.S. Genetic Information Nondiscrimination Act applies only to genetic tests.

\section{Amyloid PET and anticipated impact on patient care}

Although published data concerning amyloid PET results and impact on patient care outcome are extremely limited, amyloid PET is likely to contribute to better patient care under specific circumstances. These are described in the following three domains.

\subsection{Change in medication management}

Greater physician confidence in the diagnosis of or exclusion of AD can result in better medication management. An amyloid-positive PET result that raises confidence in the diagnosis of $\mathrm{AD}$ is likely to result in earlier and appropriate use of specific medications for symptomatic treatment of $\mathrm{AD}$, such as acetylcholinesterase inhibitors and memantine. In contrast, a plan to commence or continue medications developed for the treatment of $\mathrm{AD}$, such as the acetylcholinesterase inhibitors and possibly memantine, in patients with a negative amyloid scan may be inappropriate. However, there are no studies to date that have assessed the value of these medications in amyloid-negative persons with a clinical phenotype suggestive of AD. Furthermore, there is some evidence that acetylcholinesterase inhibitors can benefit patients with vascular dementia [69]. Exclusion of AD should result in consideration of alternate diagnoses including depression, and in some cases of patients with atypical cognitive impairment who are amyloid negative, it may be appropriate to undertake a trial of antidepressant medication.

\subsection{Change in ordering other tests}

An amyloid PET cannot answer all diagnostic questions that are encountered during clinical dementia evaluation. It can, however, reduce the use of other tests that are burdensome to patients and their caregivers. For example, a positive amyloid PET result may obviate repeat imaging for the 
purpose of establishing a clinical diagnosis of dementia whereas a negative amyloid PET result may guide clinicians to order tests that can help differentiate amyloidnegative dementing disorders. Amyloid PET may reduce the use of neuropsychological testing for the purpose of clinical diagnosis.

\subsection{Value of knowing}

Under the circumstances outlined previously, the results of amyloid PET will increase physician confidence in the clinical diagnosis and allow better planning for patients and caregivers. The following data are from a survey conducted by the Harvard School of Public Health on the public perceptions and awareness of AD [70]. The poll was commissioned by Alzheimer Europe through a grant provided by Bayer. These data and facts can be found at http://www.hsph. harvard.edu/news/press-releases/2011-releases/alzheimers-international-survey.html [71] and http://www.alz.org/ documents_custom/public-health/value_of_knowing.pdf [72].

\section{Survey Summary}

1. Nearly $89 \%$ of Americans say that if they were exhibiting confusion and memory loss, they would want to know if the cause of the symptoms was $\mathrm{AD}$.

2. Of those aged 60 years and older, $95 \%$ say they would want to know if they had AD.

3. More than $97 \%$ say that if they had a family member exhibiting problems with memory loss, they would want him or her to see a doctor to determine whether the cause was $\mathrm{AD}$.

4. The convergence of evidence from numerous sources indicates that as many as half of people with dementia have never received a diagnosis.

5. A formal diagnosis allows individuals and their caregivers to have access to available treatments, build a care team, participate in support services, and enroll in clinical trials.

6. Participating in planning early in the disease process allows individuals with $\mathrm{AD}$ to create advance directives regarding their care and finances so that their wishes can be carried out when they are no longer cognitively able to make such decisions.

7. Early diagnosis also allows individuals with the disease and their caregivers to manage medications more effectively, receive counseling, and address driving and safety issues in advance.

8. Undertaking the diagnostic process early potentially allows cognitive impairment to be reversed in some people. For nearly one in every four individuals who reported to a memory clinic with cognitive problems, their cognitive impairment was the result of a reversible cause, such as depression or a vitamin B12 deficiency.

\section{Image quality and reporting}

The clinical value of amyloid PET imaging is entirely dependent on the quality of the images and accuracy of interpretation. Amyloid PET imaging is technically challenging and should be performed only when there is strict attention to quality control. Clinical PET scanning is widely available, but the experience of PET facilities with brain imaging is quite variable. Amyloid imaging is an evolving modality; therefore, image interpretation criteria, the clinical significance of positive and negative scans, and technical imaging considerations are evolving. The following recommendations are based on current knowledge and may require modification in the future.

The safe performance and accurate interpretation of amyloid imaging require physician training as described in the nuclear medicine program requirements of the Accreditation Council for Graduate Medical Education or the equivalent. All nuclear medicine examinations should be performed under the supervision of and interpreted by a physician certified in nuclear medicine or nuclear radiology by the American Board of Nuclear Medicine or the American Board of Radiology in the United States or equivalent organizations outside the United States.

The individual performing the scan must be familiar with brain anatomy and must have adequate specific training in amyloid PET interpretation. Training specific to the interpretation of amyloid imaging such as provided by the manufacturer of the radiopharmaceutical (if available) should be completed, and preferably augmented by training programs offered by professional societies such as the SNMMI and the European Association of Nuclear Medicine.

Imaging procedures should be performed by a qualified nuclear medicine technologist with appropriate training and certification. All nuclear medicine examinations should be performed by a qualified nuclear medicine technologist who is registered/certified in nuclear medicine by the Nuclear Medicine Technology Certification Board, the American Registry of Radiologic Technologists, or equivalent organizations outside the United States. The nuclear medicine technologist should work under the supervision of a physician with qualifications outlined previously. Imaging should be performed in an imaging facility certified by the Intersocietal Commission for the Accreditation of Nuclear Laboratories, the American College of Radiology, or other equivalent accrediting agency. A procedure guideline for amyloid PET is currently being developed by the SNMMI and European Association of Nuclear Medicine.

Results of amyloid PET imaging should be communicated to the referring physician by the imaging physician by way of a written report according to a standard diagnostic imaging practice as outlined in the SNMMI General Imaging Guideline. The final reading should indicate whether $A \beta$ was found to be present (amyloid positive) or was not found to be present (amyloid negative; see Definitions). Indeterminate 
results may arise as a result of technical or physiological factors and should be reported as such.

The report should not confound amyloid positivity with $\mathrm{AD}$ dementia (i.e., it should not, by itself, advance or rule out a diagnosis of $\mathrm{AD}$ dementia). The dementia specialist should then communicate with patients and family members after comprehensive review of the clinical assessment and test results.

\section{Further research questions}

\subsection{Prognosis in healthy individuals and in patients with $M C I$}

The AIT recognized that studies suggest amyloid imaging may have a role in stratifying patients into their risk of developing cognitive decline and that, someday, as longitudinal research studies accumulate data, amyloid imaging may become useful to predict future clinical conditions, such as the risk of developing cognitive decline or of transitioning into clinical states such as MCI or dementia [10,16,21,24,27,33,73,74]. However, these studies need further replication and their results analyzed in a pooled meta-analysis [75]. Therefore, at this point, data are simply incomplete to support using amyloid imaging to provide prognostic information to persons with $\mathrm{AD}$ risk factors such as age, family history of dementia, $A P O E \varepsilon 4$ status, genetic mutation carrier status, and cognitive complaint that is unconfirmed on clinical examination, or to asymptomatic persons.

Recent data from longitudinal studies of normal elderly cohorts with positive amyloid scans show a very slow rate of decline in memory function and suggest that the process of amyloid accumulation may extend for 20 years before dementia is apparent $[10,17]$. These studies also have shown considerable variation in the rate of amyloid accumulation among individuals. The proportion of healthy elderly persons with a positive amyloid scan who will develop dementia in their lifetime is not known at this time. For this reason, scanning for amyloid in an asymptomatic person in the absence of an effective disease-modifying therapy is discouraged.

\subsection{Amyloid PET in the context of other biomarkers and diagnostic tests}

Multiple imaging modalities and fluid biomarkers have been investigated in clinical and research contexts. Brain FDG-PET has been used in a clinical setting and can be diagnostically useful in certain circumstances when a characteristic pattern of hypometabolism is detected for specific neurodegenerative disorders [76,77] -in particular, differentiation of dementing disorders in which amyloid PET are similarly positive (such as AD vs DLB) or negative (such as subtypes of FTD). Cerebrospinal fluid measures of amyloid peptides and tau have been investigated extensively and applied to research populations for the purpose of establishing the presence of AD pathology $[7,38,78,79]$, and these fluid assays are beginning to be used in clinical settings. Combined use of presynaptic dopaminergic and amyloid imaging is now being studied as a diagnostic stratification approach to aid differential diagnosis of AD, DLB, and FTD [80]. However, the effective use of these diagnostic tests in relation to amyloid PET should be investigated further in the context of patient outcome, benefit, and resource use.

\subsection{Computer software to assist image interpretation}

Computer-aided analysis software for amyloid imaging is under development, and several programs are available for use in the clinic. These programs can provide quantitative information about the amount of radiopharmaceutical in different brain regions, and may be particularly valuable for sites with limited experience in the reading of amyloid scans and to provide more information than a binary visual read. However, more research is required to validate their use in the clinical environment and demonstrate that they improve the accuracy of clinical reports.

\section{Acknowledgments}

We thank William Klunk for his expert advice to the AIT meetings and teleconferences. We thank the following individuals for rating the papers used in the evidence-based literature review:

Michael Devous, PhD; Alex Drzezga, MD; Karl Herholz, MD, FRCP; Gil Rabinovici, MD; Victor Villemagne, MD; and David Wolk, MD. In addition, we thank Kristi Mitchell and Michelle Bruno of Avalere Health for managing the conflicts of interest and the literature searches.

\section{References}

*These articles were used as the literature-based evidence for rating the AUC outlined by the Indications Subcommittee.

[1] Klunk WE, Engler H, Nordberg A, Wang Y, Blomqvist G, Holt DP, et al. Imaging brain amyloid in Alzheimer's disease with Pittsburgh compound-B. Ann Neurol 2004;55:306-19.

[2] Langa KM, Foster NL, Larson EB. Mixed dementia: emerging concepts and therapeutic implications. JAMA 2004;292:2901-8.

[3] Patel MR, Spertus JA, Brindis RG, Hendel RC, Douglas PS, Peterson ED, et al. ACCF proposed method for evaluating the appropriateness of cardiovascular imaging. J Am Coll Cardiol 2005; 46:1606-13.

[4] Fryback DG, Thornbury JR. The efficacy of diagnostic imaging. Med Decision Making 1991;11:88-94.

*[5] Landau SM, Mintun MA, Joshi AD, Koeppe RA, Petersen RC, Aisen PS, et al. Amyloid deposition, hypometabolism, and longitudinal cognitive decline. Ann Neurol 2012;72:578-86.

[6] Johnson KA, Sperling RA, Gidicsin C, Carmasin J, Maye JE, Coleman RE, et al. Florbetapir (F18-AV-45) PET to assess amyloid burden in Alzheimer's disease dementia, mild cognitive impairment, and normal aging. Alzheimers Dement In press.

[7] McKhann GM, Knopman DS, Chertkow H, Hyman BT, Jack CR Jr, Kawas CH, et al. The diagnosis of dementia due to Alzheimer's disease: recommendations from the National Institute on Aging-Alzheimer's 
Association workgroups on diagnostic guidelines for Alzheimer's disease. Alzheimers Dement 2011;7:263-9.

[8] Dubois B, Feldman HH, Jacova C, Cummings JL, Dekosky ST, Barberger-Gateau P, et al. Revising the definition of Alzheimer's disease: a new lexicon. Lancet Neurol 2010;9:1118-27.

[9] Klunk WE. Amyloid imaging as a biomarker for cerebral betaamyloidosis and risk prediction for Alzheimer dementia. Neurobiol Aging 2011;32:S20-36.

[10] Villemagne VL, Pike KE, Chetelat G, Ellis KA, Mulligan RS, Bourgeat $\mathrm{P}$, et al. Longitudinal assessment of Abeta and cognition in aging and Alzheimer disease. Ann Neurol 2011;69:181-92.

[11] Laforce R Jr, Rabinovici GD. Amyloid imaging in the differential diagnosis of dementia: review and potential clinical applications. Alzheimers Res Ther 2011;3:31.

*[12] Bacskai BJ, Frosch MP, Freeman SH, Raymond SB, Augustinack JC, Johnson KA, et al. Molecular imaging with Pittsburgh compound B confirmed at autopsy: a case report. Arch Neurol 2007;64:431-4.

*[13] Ikonomovic MD, Klunk WE, Abrahamson EE, Mathis CA, Price JC, Tsopelas ND, et al. Post-mortem correlates of in vivo PiB-PET amyloid imaging in a typical case of Alzheimer's disease. Brain 2008; 131:1630-45.

*[14] Cairns NJ, Ikonomovic MD, Benzinger T, Storandt M, Fagan AM, Shah AR, et al. Absence of Pittsburgh compound B detection of cerebral amyloid beta in a patient with clinical, cognitive, and cerebrospinal fluid markers of Alzheimer disease: a case report. Arch Neurol 2009;66:1557-62.

*[15] Clark CM, Pontecorvo MJ, Beach TG, Bedell BJ, Coleman RE, Doraiswamy PM, et al. Cerebral PET with florbetapir compared with neuropathology at autopsy for detection of neuritic amyloidbeta plaques: a prospective cohort study. Lancet Neurol 2012; 11:669-78.

*[16] Doraiswamy PM, Sperling RA, Coleman RE, Johnson KA, Reiman EM, Davis MD, et al. Amyloid-beta assessed by florbetapir F 18 PET and 18-month cognitive decline: a multicenter study. Neurology 2012;79:1636-44.

*[17] Jack CR Jr, Wiste HJ, Vemuri P, Weigand SD, Senjem ML, Zeng G, et al. Brain beta-amyloid measures and magnetic resonance imaging atrophy both predict time-to-progression from mild cognitive impairment to Alzheimer's disease. Brain 2010;133:3336-48.

*[18] Koivunen J, Pirttila T, Kemppainen N, Aalto S, Herukka SK, Jauhianen AM, et al. PET amyloid ligand [11C]PIB uptake and cerebrospinal fluid beta-amyloid in mild cognitive impairment. Dement Geriatr Cogn Disord 2008;26:378-83.

*[19] Leinonen V, Alafuzoff I, Aalto S, Suotunen T, Savolainen S, Nagren K, et al. Assessment of beta-amyloid in a frontal cortical brain biopsy specimen and by positron emission tomography with carbon 11labeled Pittsburgh compound B. Arch Neurol 2008;65:1304-9.

*[20] Mok V, Leung EY, Chu W, Chen S, Wong A, Xiong Y, et al. Pittsburgh compound B binding in poststroke dementia. J Neurol Sci 2010; 290:135-7.

*[21] Okello A, Koivunen J, Edison P, Archer HA, Turkheimer FE, Nagren K, et al. Conversion of amyloid positive and negative MCI to AD over 3 years: an 11C-PIB PET study. Neurology 2009; 73:754-60.

*[22] Rabinovici GD, Rosen HJ, Alkalay A, Kornak J, Furst AJ, Agarwal N, et al. Amyloid vs FDG-PET in the differential diagnosis of AD and FTLD. Neurology 2011;77:2034-42.

*[23] Sojkova J, Driscoll I, Iacono D, Zhou Y, Codispoti KE, Kraut MA, et al. In vivo fibrillar beta-amyloid detected using [11C]PiB positron emission tomography and neuropathologic assessment in older adults. Arch Neurol 2011;68:232-40.

*[24] Wolk DA, Price JC, Saxton JA, Snitz BE, James JA, Lopez OL, et al. Amyloid imaging in mild cognitive impairment subtypes. Ann Neurol 2009;65:557-68.

*[25] Wolk DA, Grachev ID, Buckley C, Kazi H, Grady MS, Trojanowski JQ, et al. Association between in vivo fluorine 18-labeled flutemetamol amyloid positron emission tomography imaging and in vivo cerebral cortical histopathology. Arch Neurol 2011; 68:1398-403.

*[26] Villain N, Chetelat G, Grassiot B, Bourgeat P, Jones G, Ellis KA, et al. Regional dynamics of amyloid-beta deposition in healthy elderly, mild cognitive impairment and Alzheimer's disease: a voxelwise PiB-PET longitudinal study. Brain 2012;135:2126-39.

*[27] Forsberg A, Engler H, Almkvist O, Blomquist G, Hagman G, Wall A, et al. PET imaging of amyloid deposition in patients with mild cognitive impairment. Neurobiol Aging 2008;29:1456-65.

*[28] Foster ER, Campbell MC, Burack MA, Hartlein J, Flores HP, Cairns NJ, et al. Amyloid imaging of Lewy body-associated disorders. Mov Disord 2010;25:2516-23.

*[29] Kepe V, Ghetti B, Farlow MR, Bresjanac M, Miller K, Huang SC, et al. PET of brain prion protein amyloid in Gerstmann-Straussler-Scheinker disease. Brain Pathol 2010;20:419-30.

*[30] Villemagne VL, McLean CA, Reardon K, Boyd A, Lewis V, Klug G, et al. 11C-PiB PET studies in typical sporadic Creutzfeldt-Jakob disease. J Neurol Neurosurg Psychiatry 2009;80:998-1001.

*[31] Jagust WJ, Bandy D, Chen K, Foster NL, Landau SM, Mathis CA, et al. The Alzheimer's Disease Neuroimaging Initiative positron emission tomography core. Alzheimers Dement 2010;6:221-9.

*[32] Johnson KA, Gregas M, Becker JA, Kinnecom C, Salat DH, Moran EK, et al. Imaging of amyloid burden and distribution in cerebral amyloid angiopathy. Ann Neurol 2007;62:229-34.

*[33] Morris JC, Roe CM, Grant EA, Head D, Storandt M, Goate AM, et al. Pittsburgh compound B imaging and prediction of progression from cognitive normality to symptomatic Alzheimer disease. Arch Neurol 2009;66:1469-75.

[34] Montine TJ, Phelps CH, Beach TG, Bigio EH, Cairns NJ, Dickson DW, et al. National Institute on Aging-Alzheimer's Association guidelines for the neuropathologic assessment of Alzheimer's disease: a practical approach. Acta Neuropathol 2012;123:1-11.

[35] Dubois B, Feldman HH, Jacova C, Dekosky ST, Barberger-Gateau P, Cummings $\mathrm{J}$, et al. Research criteria for the diagnosis of Alzheimer's disease: revising the NINCDS-ADRDA criteria. Lancet Neurol 2007; 6:734-46.

[36] Petersen RC. Mild cognitive impairment as a diagnostic entity. J Intern Med 2004;256:183-94.

[37] Petersen RC. Mild cognitive impairment or questionable dementia? Arch Neurol 2000;57:643-4.

[38] Albert MS, DeKosky ST, Dickson D, Dubois B, Feldman HH, Fox NC, et al. The diagnosis of mild cognitive impairment due to Alzheimer's disease: recommendations from the National Institute on Aging-Alzheimer's Association workgroups on diagnostic guidelines for Alzheimer's disease. Alzheimers Dement 2011; 7:270-9.

[39] Morris JC. Revised criteria for mild cognitive impairment may compromise the diagnosis of Alzheimer disease dementia. Arch Neurol 2012;69:700-8.

[40] Ossenkoppele R, Tolboom N, Foster-Dingley JC, Adriaanse SF, Boellaard R, Yaqub M, et al. Longitudinal imaging of Alzheimer pathology using [11C]PIB, [18F]FDDNP and [18F]FDG PET. Eur J Nucl Med Mol Imaging 2012;39:990-1000.

[41] Wey SP, Weng CC, Lin KJ, Yao CH, Yen TC, Kung HF, et al. Validation of an (18)F-labeled biphenylalkyne as a positron emission tomography imaging agent for beta-amyloid plaques. Nucl Med Biol 2009; 36:411-7.

[42] Fodero-Tavoletti MT, Mulligan RS, Okamura N, Furumoto S, Rowe CC, Kudo Y, et al. In vitro characterisation of BF227 binding to alpha-synuclein/Lewy bodies. Eur J Pharmacol 2009;617:54-8.

[43] Henriksen G, Yousefi BH, Drzezga A, Wester HJ. Development and evaluation of compounds for imaging of beta-amyloid plaque by means of positron emission tomography. Eur J Nucl Med Mol Imaging 2008;35:S75-81.

[44] Burack MA, Hartlein J, Flores HP, Taylor-Reinwald L, Perlmutter JS, Cairns NJ. In vivo amyloid imaging in autopsy-confirmed Parkinson disease with dementia. Neurology 2010;74:77-84. 
[45] Kadir A, Marutle A, Gonzalez G, Scholl M, Almkvist O, Mousavi M, et al. Positron emission tomography imaging and clinical progression in relation to molecular pathology in the first Pittsburgh compound B positron emission tomography patient with Alzheimer's disease. Brain 2011;134:301-17.

[46] Kantarci K, Yang C, Schneider JA, Senjem ML, Reyes DA, Lowe VJ, et al. Ante mortem amyloid imaging and beta-amyloid pathology in a case with dementia with Lewy bodies. Neurobiol Aging 2012; $33: 878-85$.

[47] Ikonomovic MD, Abrahamson EE, Price JC, Hamilton RL, Mathis CA, Paljug WR, et al. Early AD pathology in a [C-11]PiBnegative case: a PiB-amyloid imaging, biochemical, and immunohistochemical study. Acta Neuropathol 2012;123:433-47.

[48] Vandenberghe R, Van Laere K, Ivanoiu A, Salmon E, Bastin C, Triau E, et al. 18F-flutemetamol amyloid imaging in Alzheimer disease and mild cognitive impairment: a phase 2 trial. Ann Neurol 2010;68:319-29.

[49] Rowe CC, Ackerman U, Browne W, Mulligan R, Pike KL, O'Keefe G, et al. Imaging of amyloid beta in Alzheimer's disease with 18FBAY94-9172, a novel PET tracer: proof of mechanism. Lancet Neurol 2008;7:129-35.

[50] Vallabhajosula S. Positron emission tomography radiopharmaceuticals for imaging brain beta-amyloid. Semin Nucl Med 2011; 41:283-99.

[51] Cselenyi Z, Jonhagen ME, Forsberg A, Halldin C, Julin P, Schou M, et al. Clinical validation of 18F-AZD4694, an amyloid-beta-specific PET radioligand. J Nucl Med 2012;53:415-24.

[52] Jureus A, Swahn BM, Sandell J, Jeppsson F, Johnson AE, Johnstrom P, et al. Characterization of AZD4694, a novel fluorinated Abeta plaque neuroimaging PET radioligand. J Neurochem 2010; 114:784-94.

[53] Rowe CC, Pejoska S, Mulligan RS, Gareth Jones G, Chan JG, Svensson S, et al. Head to head comparison of 11C-PiB and 18F-AZD4694 (NAV4694) for A $\beta$ imaging in ageing and dementia. J Nucl Med In press.

[54] Rinne JO, Wong DF, Wolk DA, Leinonen V, Arnold SE, Buckley C, et al. [(18)F]Flutemetamol PET imaging and cortical biopsy histopathology for fibrillar amyloid beta detection in living subjects with normal pressure hydrocephalus: pooled analysis of four studies. Acta Neuropathol 2012;124:833-45.

[55] Wolk DA, Zhang Z, Boudhar S, Clark CM, Pontecorvo MJ, Arnold SE. Amyloid imaging in Alzheimer's disease: comparison of florbetapir and Pittsburgh compound-B positron emission tomography. J Neurol Neurosurg Psychiatry 2012;83:923-6.

[56] Landau SM, Breault C, Joshi AD, Pontecorvo M, Mathis CA, Jagust WJ, et al. Amyloid-beta imaging with Pittsburgh compound $\mathrm{B}$ and florbetapir: comparing radiotracers and quantification methods. J Nucl Med 2013;54:70-7.

[57] Villemagne VL, Mulligan RS, Pejoska S, Ong K, Jones G, O'Keefe G, et al. Comparison of 11C-PiB and 18F-florbetaben for Abeta imaging in ageing and Alzheimer's disease. Eur J Nucl Med Mol Imaging 2012; 39:983-9.

[58] Foster NL, Heidebrink JL, Clark CM, Jagust WJ, Arnold SE, Barbas NR, et al. FDG-PET improves accuracy in distinguishing frontotemporal dementia and Alzheimer's disease. Brain 2007; 130:2616-35.

[59] Rowe CC, Ellis KA, Rimajova M, Bourgeat P, Pike KE, Jones G, et al. Amyloid imaging results from the Australian Imaging, Biomarkers and Lifestyle (AIBL) study of aging. Neurobiol Aging 2010; 31:1275-83.

[60] Morris JC, Roe CM, Xiong C, Fagan AM, Goate AM, Holtzman DM, et al. APOE predicts amyloid-beta but not tau Alzheimer pathology in cognitively normal aging. Ann Neurol 2010;67:122-31.

[61] Gomperts SN, Rentz DM, Moran E, Becker JA, Locascio JJ, Klunk WE, et al. Imaging amyloid deposition in Lewy body diseases. Neurology 2008;71:903-10.
[62] Edison P, Rowe CC, Rinne JO, Ng S, Ahmed I, Kemppainen N, et al. Amyloid load in Parkinson's disease dementia and Lewy body dementia measured with [11C]PIB positron emission tomography. J Neurol Neurosurg Psychiatry 2008;79:1331-8.

[63] Greenberg SM, Grabowski T, Gurol ME, Skehan ME, Nandigam RN, Becker JA, et al. Detection of isolated cerebrovascular beta-amyloid with Pittsburgh compound B. Ann Neurol 2008; 64:587-91.

[64] Haglund M, Sjobeck M, Englund E. Severe cerebral amyloid angiopathy characterizes an underestimated variant of vascular dementia. Dement Geriatr Cogn Disord 2004;18:132-7.

[65] Natte R, Maat-Schieman ML, Haan J, Bornebroek M, Roos RA, van Duinen SG. Dementia in hereditary cerebral hemorrhage with amyloidosis-Dutch type is associated with cerebral amyloid angiopathy but is independent of plaques and neurofibrillary tangles. Ann Neurol 2001;50:765-72.

[66] Ly JV, Rowe CC, Villemagne VL, Zavala JA, Ma H, O'Keefe G, et al. Cerebral beta-amyloid detected by Pittsburgh compound B positron emission topography predisposes to recombinant tissue plasminogen activator-related hemorrhage. Ann Neurol 2010;68:959-62.

[67] Gurol ME, Viswanathan A, Gidicsin C, Hedden T, Martinez SR, Dumas A, et al. Cerebral amyloid angiopathy burden associated with leukoaraiosis: a PET/MRI study. Ann Neurol In press.

[68] Tomiyama T, Nagata T, Shimada H, Teraoka R, Fukushima A, Kanemitsu $\mathrm{H}$, et al. A new amyloid beta variant favoring oligomerization in Alzheimer's-type dementia. Ann Neurol 2008;63:377-87.

[69] Roman GC, Wilkinson DG, Doody RS, Black SE, Salloway SP, Schindler RJ. Donepezil in vascular dementia: combined analysis of two large-scale clinical trials. Dement Geriatr Cogn Disord 2005; 20:338-44.

[70] Blendon RJ, Benson JM, Wikler EM, Weldon KJ, Georges J, Baumgart $\mathrm{M}$, et al. The impact of experience with a family member with Alzheimer's disease on views about the disease across five countries. Int J Alzheimers Dis 2012. In press.

[71] Harvard School of Public Health. International Survey Highlights Great Public Desire to Seek Early Diagnosis of Alzheimer's. Available at: http://www.hsph.harvard.edu/news/press-releases/2011-releases/ alzheimers-international-survey.html. Accessed: January 11, 2013.

[72] Alzheimer's Association. Early Detection. Available at: http://www. alz.org/publichealth/early-detection.asp. Accessed January 11, 2013.

[73] Choo IH, Ni R, Scholl M, Wall A, Almkvist O, Nordberg A. Combination of 18F-FDG PET and cerebrospinal fluid biomarkers as a better predictor of the progression to Alzheimer's disease in mild cognitive impairment patients. J Alzheimers Dis. In press.

[74] Nordberg A, Carter SF, Rinne J, Drzezga A, Brooks DJ, Vandenberghe R, et al. A European multicentre PET study of fibrillar amyloid in Alzheimer's disease. Eur J Nucl Med Mol Imaging 2013; 40:104-14.

[75] Ioannidis JP, Panagiotou OA. Comparison of effect sizes associated with biomarkers reported in highly cited individual articles and in subsequent meta-analyses. JAMA 2011;305:2200-10.

[76] Herholz K, Carter SF, Jones M. Positron emission tomography imaging in dementia. Br J Radiol 2007;80:S160-7.

[77] Bohnen NI, Minoshima S. FDG-PET and molecular brain imaging in the movement disorders clinic. Neurology 2012;79:1306-7.

[78] Shaw LM, Vanderstichele H, Knapik-Czajka M, Clark CM, Aisen PS, Petersen RC, et al. Cerebrospinal fluid biomarker signature in Alzheimer's disease neuroimaging initiative subjects. Ann Neurol 2009; 65:403-13.

[79] Fagan AM, Head D, Shah AR, Marcus D, Mintun M, Morris JC, et al. Decreased cerebrospinal fluid Abeta(42) correlates with brain atrophy in cognitively normal elderly. Ann Neurol 2009;65:176-83.

[80] Burke JF, Albin RL, Koeppe RA, Giordani B, Kilbourn MR, Gilman S, et al. Assessment of mild dementia with amyloid and dopamine terminal positron emission tomography. Brain 2011; 134:1647-57. 


\section{Appendix A: Task force members and literature reviewers}

\author{
Task Force Members (alphabetical) \\ Co-chairs (alphabetical) \\ Keith Johnson, MD \\ Satoshi Minoshima, MD, PhD (Co-chair) \\ Voting Members (alphabetical) \\ Nicolaas Bohnen, MD, PhD \\ Kevin Donohoe, MD \\ Norman Foster, MD \\ Peter Herscovitch, MD \\ Keith Johnson, MD \\ Jason Karlawish, MD \\ Satoshi Minoshima, MD, PhD \\ Christopher Rowe, MD \\ Scientific Advisor \\ William Klunk, MD, PhD
}

Society of Nuclear Medicine and Molecular Imaging

(SNMMI) and the Alzheimer's Association (AA) AA

Members (alphabetical)

Maria Carrillo, PhD (AA)

Dean Hartley, PhD (AA)

Saima Hedrick, MPH (SNMMI)

Kristi Mitchell MPH (Avalere Health)

Virginia Pappas, CAE (SNMMI)

William Thies, $\mathrm{PhD}$ (AA)

Indication Subcommittee (alphabetical)

Norman L. Foster, MD (chair)

Jason Karlawish, MD

Christopher Rowe, MD

Literature Subcommittee (alphabetical)

Nicolaas Bohnen, MD, PhD (chair)

Peter Herscovitch, MD

Kristi Mitchell MPH

Literature Reviewers (alphabetical)

Nicolaas Bohnen, MD PhD

Michael Devous, $\mathrm{PhD}$

Kevin Donohoe, MD

Alex Drzezga, MD

Karl Herholz, MD, FRCP

Peter Herscovitch, MD

Keith Johnson, MD

Jason Karlawish, MD

Satoshi Minoshima, MD, PhD

Gil Rabinovici, MD

Christopher Rowe, MD

Victor Villemagne, MD

David Wolk MD

\section{Appendix B: Indications Subcommittee}

The Expert Work Group consisted of three experienced clinicians, two geriatric cognitive neurologists, and a geriatrician. The developed guidelines for appropriate and inappropriate clinical use are based on available literature as well as expert opinion using a modified Delphi procedure. The first task of the work group was to individually rate appropriateness of 115 different clinical scenarios based on the seven variables listed in Table B1. Beginning with the premise that there is value in determining the cause of cognitive impairment, each expert weighed the potential clinical value of amyloid positron emission tomography (PET) against the expense and potential for misuse. After reporting the outcome of these individually considered judgments, the experts came to a consensus about each of the scenarios and used these conclusions to draw generalizations that should be applicable to many different scenarios.

A second task of the work group was to consider the utility of amyloid PET in eight situations when syndrome classification would be clinically important (e.g., delirium vs dementia) and in 40 clinically relevant differential diagnosis decision points (e.g., Alzheimer's disease vs. frontotemporal dementia). Last, the three clinicians jointly reviewed 10 actual anonymous clinical cases to test whether the guidelines they constructed accurately reflected their own clinical judgment in real rather than strictly theoretical situations. All voting members of the Amyloid Imaging Taskforce (AIT) reviewed and discussed the expert-recommended guidelines, and comments were elicited from within and beyond the work group. The final expert guidelines reflect this entire process and are the joint opinion of the entire AIT.

In our deliberations, we assumed that the expert clinician would receive an interpretation of the amyloid PET study as either positive or negative (see Definitions). Briefly, a positive amyloid PET result typically means that the image demonstrates uptake of amyloid radiotracer in the gray matter. In contrast, a negative scan means that the image does not demonstrate any gray matter cortical uptake that is above the level of nonspecific binding. The determination of cortical uptake relies on inspection of the contrast between white matter and cortical gray matter. In white matter, imaging ligands are routinely visible not as a result of their binding to amyloid, but as a result of lipophilic interactions with myelin. Some ligands have greater white matter uptake than others. Histopathology-to-PET correlation studies relating amyloid PET results with neuropathological measures of amyloid plaques, using both immunohistochemistry or silver staining, have shown that if amyloid plaques are none or sparse, amyloid imaging ligand-specific binding in cortical gray matter is very low and reflects nonspecific (i.e., nonamyloid) binding. In contrast, when histopathological evidence at autopsy confirms the presence of frequent amyloid plaque, the amyloid image contrast between white and gray is greatly reduced or visually undetectable.

The AIT did not consider the potential impact on the appropriate use criteria of the use of quantitative PET data (i.e., data from automated numerical measurements of specific ligand binding). Quantitative measurement entails image processing steps in which specific brain regions are identified in each individual data set for the purpose of comparing regional cortical tracer uptake with an unaffected reference 
region. Currently, there is insufficient published data to recommend a specific implementation of amyloid PET quantitation that could be identified in the appropriate use criteria.

Table B1

Variables considered in constructing clinical presentation scenarios

\begin{tabular}{ll}
\hline Scenario variable & Variations considered \\
\hline Symptoms & None \\
Clinical setting & Memory or cognitive complaint \\
& Nonmedical \\
& PCP \\
& Specialist \\
Clinical context & Dementia specialist \\
& Not applicable (nonmedical) \\
& Initial assessment \\
Evidence of deficit on & Full evaluation, AD not suspected \\
examination & Full evaluation, AD suspected \\
& Not applicable (nonmedical) \\
& None \\
& Yes \\
Family history of AD or & MCI \\
apolipoprotein E $\varepsilon 4$ positive & Mild-moderate dementia \\
AD genetic mutation carrier & Severe dementia \\
& Negative \\
& Positive \\
Age & Negative \\
& Positive \\
& Not applicable \\
& $<65$ years \\
& $>65$ years \\
\hline
\end{tabular}

Abbreviations: PCP, Primary Care Physician; AD, Alzheimer's disease; MCI, mild cognitive impairment.

\section{Appendix C: Literature Subcommittee and evidence review}

The Literature Subcommittee used a search strategy as established by the American Academy of Neurology and the National Institutes of Medicine to identify relevant literature. Multiple searches were performed using the National Institutes of Health's PubMed in which 408 publications were initially identified. Literature search limits and parameters were as follow: human, English, and publication date January 01, 2002 to the present. The search terms determined to be the most useful for identifying the pertinent literature were (i) Florbetapir and AV-45, or Amyvid; (ii) PiB or Pittsburgh compound B; (iii) flutemetamol or AV1; (iv) F18 FDDNP or F18 FDDNP; and (v) florbetaben or 8FBAY94-9172.

Using the PubMed-generated list of 408 documents, the Literature Subcommittee reviewed the list for inclusion and identified a subset of documents by abstract analysis. Documents not relevant for clinical use of amyloid positron emission tomography (PET) were eliminated based on the primary focus of the study and data presented in the document. These include radiochemistry study, in vitro study, animal toxicity study, biodistribution study, image and kinetic analysis study, dosimetry study, pathophysiological investigation, correlational study, study with a small number of subjects, surrogate marker study in therapeutic trials, and review and editorial commentary. In addition, to ensure appropriate documents were captured during the initial search and review, the Amyloid Imaging Taskforce (AIT) performed a backward review to cross-check the literature included in seminal amyloid imaging reviews with those included in the AIT's initial assessment. For the backward review, the AIT used the bibliographies of Klunk [8], Villemagne and colleagues [9], and Laforce Rabinovici [10].

The Literature Subcommittee developed a data extraction form for the evidence assessment. The data extraction form included multiple questions and data extraction sections including whether the document addresses one or more of the potential indications/nonindications proposed by the Indication Subcommittee, individual data points for recalculation of the data, study design, study logistics, patient recruitment setting, inclusion/exclusion criteria, criteria used for diagnosis, inclusion of control subjects, subject characteristics, type of radiopharmaceuticals used, type of PET scanner used, method of PET interpretation and analysis, $2 \times 2$ data extraction for histopathologically confirmed study as well as mild cognitive impairment to Alzheimer's disease conversion study, a 19-point quality score of the document, the American Academy of Neurology Level of Evidence for a Diagnostic Study Article, the American Academy of Neurology Level of Evidence for a Prognostic Study Article, and whether the document addressed changes in physician confidence.

\section{Appendix D: Relationships with industry and management of conflicts of interest}

The Alzheimer's Association and the Society of Nuclear Medicine and Molecular Imaging rigorously attempted to avoid any actual, perceived, or potential conflicts of interest (COIs) that might have arisen as a result of an outside relationship or personal interest of the writing committee members of the Amyloid Imaging Taskforce (AIT) or of external reviewers used to review specific documents. Both organizations reviewed their own industry relationship policies to ensure that the ensuing process adhered to both standards.

AIT members were required to provide disclosure statements of all relationships that might be perceived as real or potential COIs. These statements were reviewed and discussed by the AIT co-chairs, and were updated and reviewed by an objective third party at the beginning of every AIT meeting and/or teleconference. A table of disclosures for AIT members and external literature reviewers can be found in Table D1.

To adjudicate the COIs, the leadership from the Alzheimer's Association and the Society of Nuclear Medicine and Molecular Imaging first determined the threshold for a real COI. After consulting with various experts and reviewing other policies used, the team defined COIs as the following: An individual who has relationships with industry, including consulting, speaking, research, and other 
nonresearch activities that exceed $\$ 5000$ in funding over the previous or upcoming 12-month period.

In addition, if external expert reviewers of the documents were either a principle investigator or other key study personnel on a study, their participation in the review would likely present a COI. All reviewers completed COI forms. Document authors and sponsors were identified and then cross-checked against reviewers' financial and intellectual COIs. Conflicted individuals were noted as unable to review documents in which there was a real COI present.

Of note, William Klunk, MD, co-invented the PiB-class and Chrysamine-G-class amyloid imaging agents, was appointed as an advisor to the AIT, contributing expertise as requested, but recused himself from any and all discussions that resulted in a vote among writing committee members.

Table D1

Table of relationships with industry and other entities for task force members and outside reviewers

\begin{tabular}{|c|c|}
\hline Name & $\begin{array}{l}\text { Reported relationships with industry or other } \\
\text { entities }\end{array}$ \\
\hline Bohnen, Nic & - None \\
\hline Devous, Michael & $\begin{array}{l}\text { - Avid Pharmaceuticals } \\
\text { - Lilly Healthcare } \\
\text { - Bayer (now Piramal Pharmaceuticals) }\end{array}$ \\
\hline Donohoe, Kevin & - None \\
\hline Drzezga, Alexander & $\begin{array}{l}\text { - Avid Radiopharmaceuticals/Lilly Healthcare } \\
\text { - Bayer Healthcare } \\
\text { - GE Healthcare } \\
\text { - Siemens Healthcare }\end{array}$ \\
\hline Foster, Norman & $\begin{array}{l}\text { - Bristol-Meyers Squibb } \\
\text { - GE Healthcare } \\
\text { - Janssen AI } \\
\text { - Center for Health Improvement }\end{array}$ \\
\hline Herholz, Karl & $\begin{array}{l}\text { - GE Healthcare } \\
\text { - Elan } \\
\text { - Avid Radiopharmaceuticals/Lilly Healthcare }\end{array}$ \\
\hline Herscovitch, Peter & - None \\
\hline Johnson, Keith & $\begin{array}{l}\text { - Siemens } \\
\text { - Avid Radiopharmaceuticals/Lilly Healthcare } \\
\text { - Janssen AI } \\
\text { - Bayer } \\
\text { - Navidea Biopharmaceuticals } \\
\text { - Piramal Healthcare }\end{array}$ \\
\hline Karlawish, Jason & $\begin{array}{l}\text { - Alzheimer's Disease Cooperative Study } \\
\text { (member) }\end{array}$ \\
\hline Minoshima, Satoshi & - None \\
\hline Rabinovici, Gil & - Avid Radiopharmaceuticals \\
\hline Rowe, Christopher & $\begin{array}{l}\text { - Bayer } \\
\text { - GE Healthcare } \\
\text { - AstraZeneca } \\
\text { - Piramal Healthcare } \\
\text { - Avid Radiopharmaceuticals/Lilly Healthcare } \\
\text { - Navidea Biopharmaceuticals }\end{array}$ \\
\hline Villemagne, Victor & - Bayer \\
\hline Wolk, David & $\begin{array}{l}\text { - Pfizer } \\
\text { - GE Healthcare }\end{array}$ \\
\hline
\end{tabular}

\section{Appendix E: Public commentary}

The Amyloid Imaging Taskforce solicited information from all communities through the Society of Nuclear Medicine and Molecular Imaging and the Alzheimer's Association websites and by direct solicitation to members of these societies. The comments and input helped to shape the development of these appropriate use criteria and the consensus recommendation for the appropriate use of amyloid imaging for clinical indications of the detection of fibrillar amyloid in the brain. 